\begin{tabular}{|c|l|}
\hline Title & $\begin{array}{l}\text { Synovial chondromatosis of the temporomandibular joint accompanied by loose bodies in both the superior and inferior } \\
\text { joint compartments: case report }\end{array}$ \\
\hline Author(s) & Sato, Jun; Notani, Ken-ichi; Goto, Jun; Shindoh, Masanobu; Kitagawa, Y oshimasa \\
\hline Citation & $\begin{array}{l}\text { International Journal of Oral and Maxillofacial Surgery, 39(1), 86-88 } \\
\text { https://doi.org/10.1016/.ijom.2009.07.012 }\end{array}$ \\
\hline Issue Date & $2010-01$ \\
\hline Doc URL & http://hdl.handle.net/2115/42785 \\
\hline Type & article (author version) \\
\hline File Information & IJOMS39-1_86-88.pdf \\
\hline
\end{tabular}

Instructions for use 


\section{Synovial chondromatosis of the temporomandibular joint accompanied by loose bodies in both the superior and inferior joint compartments: report of a case}

${ }^{\mathrm{a}}$ Jun Sato, DDS, PhD, ${ }^{\mathrm{b}}$ Ken-ichi Notani, DDS, PhD,

c Jun Goto, DDS, d Masanobu Shindoh, DDS, PhD,

e Yoshimasa Kitagawa, DDS, PhD

a Assistant professor, Department of Oral Diagnosis and Medicine,

Division of Oral Pathobiological Science, Hokkaido University, Graduate

School of Dental Medicine, Sapporo, 060-8586, Japan.

${ }^{\mathrm{b}}$ Clinical professor, Department of Oral Diagnosis and Medicine, Division of Oral Pathobiological Science, Hokkaido University, Graduate School of Dental Medicine, Sapporo, 060-8586, Japan.

${ }^{\mathrm{c}}$ Graduate student, Department of Oral Diagnosis and Medicine, Division of Oral Pathobiological Science, Hokkaido University, Graduate School of Dental Medicine, Sapporo, 060-8586, Japan.

${ }^{\mathrm{d}}$ Professor and Chairman, Department of Oral Pathology and Biology, Hokkaido University, Graduate School of Dental Medicine, Sapporo 0608586, Japan.

${ }^{\mathrm{e}}$ Professor and Chairman, Department of Oral Diagnosis and Medicine, Division of Oral Pathobiological Science, Hokkaido University, Graduate School of Dental Medicine, Sapporo 060-8586, Japan.

Corresponding author and reprint request: Jun Sato

Oral Diagnosis and Medicine, Department of Oral Pathobiological Science, Hokkaido University Graduate School of Dental Medicine, North 13, West 7, Kita-ku, Sapporo 060-8586, Japan.

Fax/phone: +81-11-706-42800

e-mail: jun-s@den.hokudai.ac.jp

Key words: synovial chondromatosis, temporomandibular joint, loose body, inferior joint compartment 


\begin{abstract}
Synovial chondromatosis (SC) of the temporomandibular joint (TMJ) is a benign lesion characterized by the formation of metaplastic cartilaginous nodules. SC of the TMJ usually only affects the superior joint compartment of the TMJ. We report a rare case of SC of the TMJ affecting the inferior as well as superior joint compartments.
\end{abstract}


Synovial chondromatosis (SC) of the temporomandibular joint (TMJ) is a rare benign condition characterized by the formation of metaplastic cartilaginous nodules in the synovium and joint space. ${ }^{1-5,7,9}$ To our knowledge, 87 cases of SC of the TMJ have been reported to date, ${ }^{6}$ and of those, only the synovial lining of the superior joint space was involved. ${ }^{3,5}$ We report a rare case of SC of the TMJ accompanied by multiple looses bodies in both the superior and inferior joint compartments.

\section{Case report}

A 74-year-old woman presented with a complaint of left TMJ pain during jaw movement, which she had had for about 10 years. There was no history of trauma. Upon physical examination, a slight swelling in the left preauricular region was found and her maximal mouth opening was $35 \mathrm{~mm}$ with pain. Panoramic radiography and computed tomography (CT) revealed multiple calcified bodies in the anterior part of the left condyle. (Fig. 1A) Magnetic resonance imaging (MRI) revealed normal position of the disk, normal contour of the condyle, and some calcifications in the expanded superior joint space. MRI also showed expansion of the inferior joint space. (Fig. 1B) Following a clinical diagnosis of the SC of the left TMJ, open-surgery using a preauricular approach was performed. Upon opening the superior joint space, viscous fluid containing multiple milkywhite loose bodies of 1 to $5 \mathrm{~mm}$ in diameter discharged. Using an arthroscope, all remaining loose bodies were located and removed from the superior joint space. Arthroscopic findings revealed only slight inflammation of the synovium without pedunculated lesions. When the inferior joint space was opened, several similar sized particles were found and similarly removed (Fig 2). About 150 and 30 loose bodies were 
removed from the superior and inferior joint spaces, respectively. The disk was in clinically normal position without perforation, so diskectomy and synovectomy were not performed.

Histological evaluation confirmed the both loose bodies from the superior and inferior compartments to be comprised of mature cartilage, some with presence of synovium-like lining of connective tissue (Fig 3A and B).

After surgery, the patient recovered well without temporary facial nerve palsy. Regular post-operative follow up examinations over 30 months showed complete resolution of symptoms and X-ray showed no recurrence of lesion.

\section{Discussion}

It has been suggested that SC of the TMJ affects only the synovial lining of the superior compartment. ${ }^{5,10}$ In our review, 5 of the 87 published cases (6\%) of SC of the TMJ involved not only the superior compartment but also the inferior compartment. ${ }^{5,8,10}$ Holmulund et al. speculated that loose bodies in the inferior joint space originated from the upper compartment following perforation of the articular disk. ${ }^{5}$ In our review of those five cases, two showed perforation of the disk. ${ }^{5,8}$ However, the reports of the remaining three cases did not describe the perforation of the disk. ${ }^{6,8,10} \mathrm{In}$ the present case, no perforation was evident under arthroscopic observation. The inferior joint space was revealed as expanded in pre-operative MRI, and subsequently found to contain about 30 loose bodies. We believe this is the first report of histologically confirmed loose bodies in the inferior joint space. 
The pathogenesis of SC is more of an active metaplastic than a neoplastic process. ${ }^{4}$ Although the pathogenesis of SC is poorly understood, the chondrocytes in loose bodies are thought to arise from the primitive mesenchymal cells in synovium. ${ }^{1,2,9}$ The trigger mechanisms of metaplasia are largely unknown, but trauma and inflammation have been mentioned as possible causes. ${ }^{1}$ As long as synovial membrane exists and receives some pressure, SC can develop even in the inferior compartment of the TMJ. We think it is natural that SC of the TMJ affects also the synovial lining of the inferior compartment. To our regret, we cannot display any similarities or differences in pathology of the synovium between the superior and inferior joint compartments, because we did not perform synovial biopsies of both compartments.

Since, the inferior joint compartment is narrower, and the area of the synovial membrane in the inferior compartment is smaller, its ability to produce loose bodies must be less than that of the superior compartment. Moreover, we can speculate that some loose bodies in the inferior compartment may have been overlooked because of inadequate investigation. Although MRI is helpful for diagnosis of SC, ${ }^{3,4}$ MRI findings of loose bodies in the inferior joint space were demonstrated in only 3 of the 87 cases (3\%). Even in operation findings, there were records of involvement of the inferior joint compartment in just 26 of 87 cases (30\%). In our case, involvement of the inferior joint space was confirmed by per-operative MRI and operation findings. In general, it is difficult to predict lesions in the inferior joint compartment from clinical symptoms. Indeed, some of the symptoms of the above 5 cases were similar to those of the other 82, such as unilateral swelling over the joint area, pain in the joint area, and limitation of jaw movement. In our case, the patient also 
complained of unilateral TMJ pain, swelling in the left preauricular region, and limitation of jaw movement.

The therapy of SC as described in the literature ranges from nonsurgical treatment through operative removal of only the particles to removal of particles with resection of synovium, condyle, and disk. ${ }^{1} \mathrm{~A}$ total resection of the synovial membrane has been advocated because the remnants may be a source of recurrence. ${ }^{4}$ However, various treatments have been used for SC of the TMJ. Synovectomy may not be required if only loose bodies are found without involvement of the synovium. In our case, the synovium was diagnosed as having only slight inflammation by arthroscopy, and the disk did not show any abnormalities. Consequently, we decided to conserve the disk and synovium to keep the structure and functions of the TMJ. Inadequate removal of such loose bodies may lead to recurrence, and malignant transformation of the disease, ${ }^{6}$ so consideration should be given to the possible involvement of SC in the inferior joint compartment of the TMJ. 


\section{Figure legends}

Figure 1: Preoperative CT (A) and MRI (B)

Axial CT showed multiple calcified bodies in the anterior part of the left condyle (arrowhead). MRI revealed normal position of the disk and some calcifications in the expanded superior joint spaces. MRI also showed expansion of the inferior joint space (arrow)

Figure 2: Surgical finding of the inferior joint compartment.

Multiple particles discharged from the inferior joint space. Small arrowhead: condyle, arrow: loose bodies, big arrowhead: disk.

Figure 3: The histological findings of the loose bodies from the superior (A) and inferior (B) compartments.

All loose bodies comprised of mature cartilage, some of which had lining of synovium-like connective tissue (hematoxylin-eosin, original magnification X100). 


\section{Acknowledgements}

We thank to Dr. Masaaki Saitoh who contributed to our research.

\section{Conflict of Interest}

We certify that our manuscript is free of conflict of interest.

Funding: None

Ethical approval: Not required 


\section{References}

1. Blankestijn J, Panders AK, Vermey A, Scherpbier AJ. Synovial chondromatosis of the temporomandibular joint. Report of three cases and a review of the literature. Cancer 1985: 55: 479-485.

2. Carls ER, Von Hochstetter A, Engelke W, Sailer HF. Loose bodies in the temporomandibular joint: The advantage of arthroscopy. J Cranio maxillofac Surg 1995: 23: 215-221.

3. Fujita S, Iizuka T, Yoshida H, Segami N. Transforming growth factor and tenascin in synovial chondromatosis of the temporomandibular joint. Report of a case. Int J Oral Maxillofac Surg 1997: 26: 258-259.

4. Holmlund A, Reinholt F, Bergstedt H. Synovial chondromatosis of the temporomandibular joint. Report of a case. Oral Surg Oral Med Oral Pathol Oral Radiol Endod 1992: 73: 266-268.

5. Holmlund AB, Eriksson L, Reinholt FP. Synovial chondromatosis of the temporomandibular joint. Clinical, surgical and histological aspects. Int J Oral Maxillofac Surg 2003: 32: 143-147.

6. Mandrioli S, Polito J, Denes SA, Clauser L. Synovial chondromatosis of the temporomandibular joint. J Craniofac Surg 2007: 18: 1486-1488.

7. Milgram JW. The classification of loose bodies in human joints. Clin Orthop Relat Res 1977: 124: 282-291. 
8. Petito AR, Bennett J, Assael LA, Carlotti, AE., Jr. Synovial chondromatosis of the temporomandibular joint: varying presentation in 4 cases. Oral Surg Oral Med Oral Pathol Oral Radiol Endod 2000: 90: 758-764.

9. Sato J, Segami N, Suzuki T, Yoshitake Y, Nishikawa K. The expression of fibroblast growth factor-2 and fibroblast growth factor receptor-1 in chondrocytes in synovial chondromatosis of the temporomandibular joint. report of two cases. Int J Oral Maxillofac Surg 2002: 31: 532-536.

10. Sembronio S, Albiero AM, Toro C, Robiony M, Politi M. Arthroscopy with open surgery for treatment of synovial chondromatosis of the temporomandibular joint. Br J Oral Maxillofac Surg 2008: 46: 582-584. 


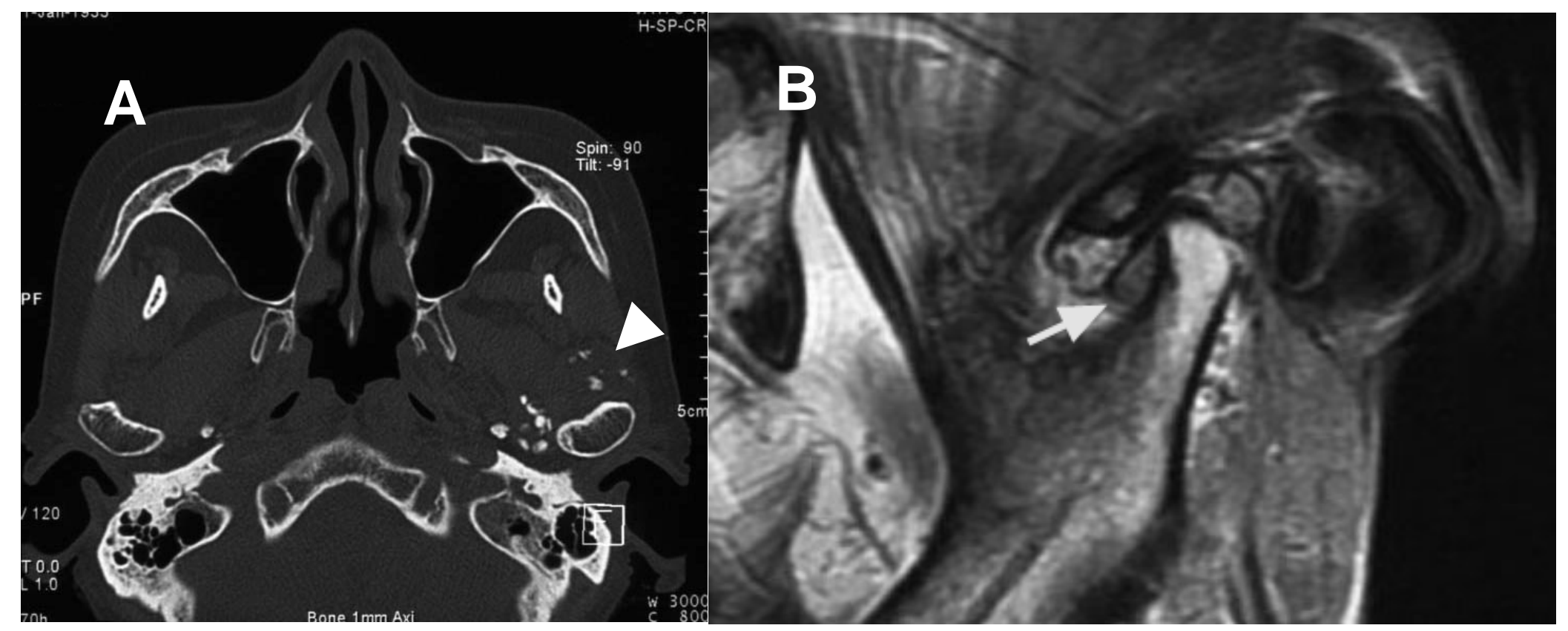

Fig. 1 


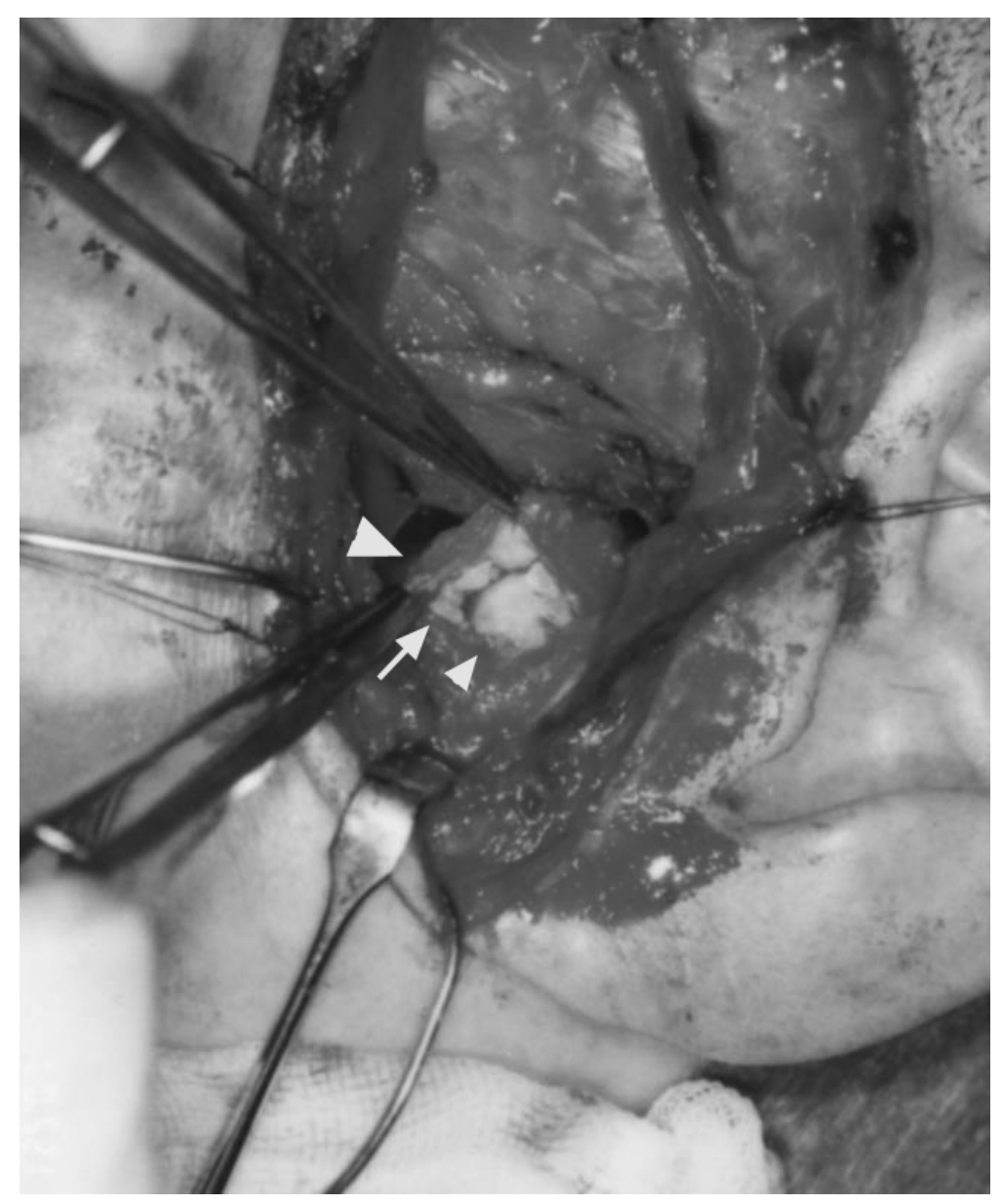

Fig. 2 


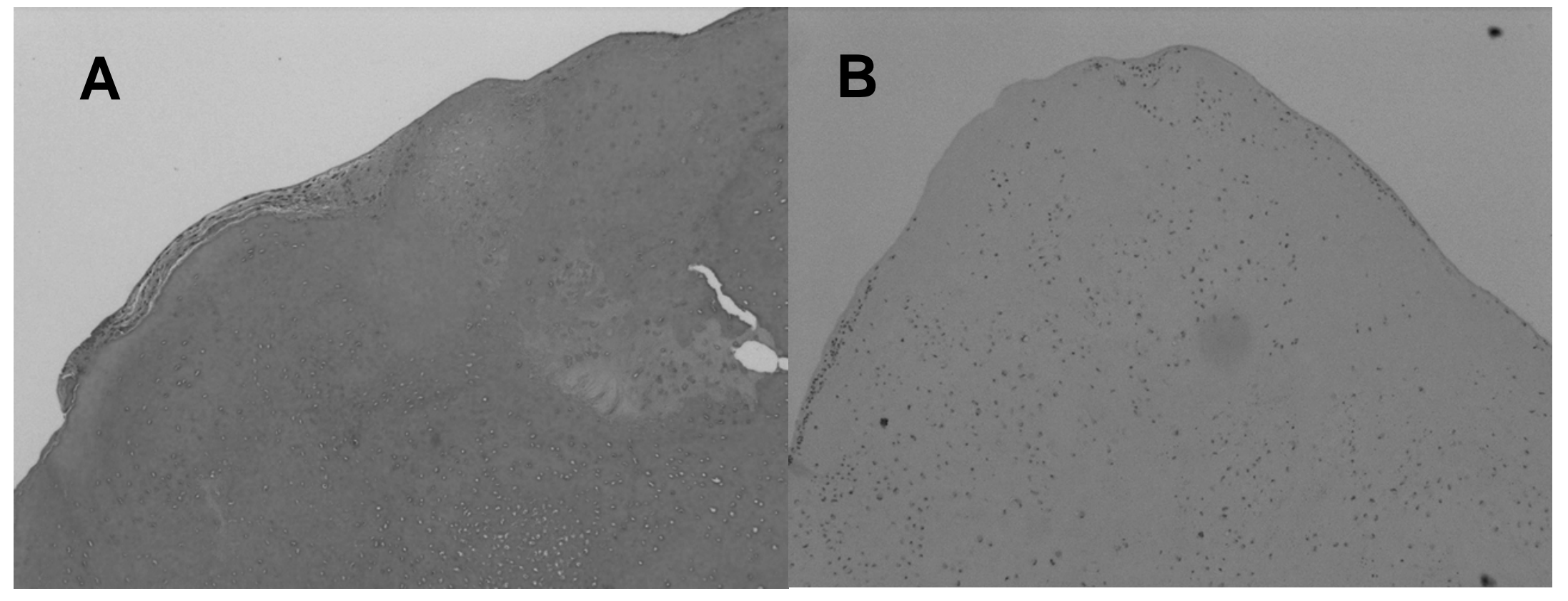

Fig. 3 